\title{
An Exploration by Way of Introduction: Design and the Having of Designs in Ireland
}

\author{
Adam Drazin and Pauline Garvey
}

Nearly three hundred years ago Edmund Burke, one of our famous Irish writers, said 'a state without the means of some change is without the means of its conservation'. Today that means of change is technology.

(Bertie Ahern, Taoiseach of the Republic of Ireland 2003)

Ireland, both North and South, has gained international prominence in recent years for the startling economic transformations it has achieved. Many governments study the example of the Republic of Ireland and attempt to learn the recipe of the 'Irish Model' in which, as implied in the quote above, technology and design play a part. Key elements in the narrative of Irish national transformation are manufacturing and processing plants, established by companies whose names evoke the feeling of a contemporary hi-tech global zeitgeist. Microsoft, Intel, Hewlett-Packard, Rank Xerox and others, all have major plants for their core products, which can roll off a production line but are intricately engineered. Several of these companies have also established head offices in Ireland, overseeing European operations. Dublin has therefore become an international leader in hi-tech components, software engineering and pharmaceuticals.

In the wake of these developments, Ireland also symbolically represents the next stage in the contemporary mythical trajectory of national socio-economic success. To maintain success, government policy in Ireland has been attempting to move the technological sector from manufacturing and white-collar management into design. This is widely understood as the building of a 'knowledge economy'. At the time of writing, in the wake of a global banking collapse, Ireland has been confirmed as being even more exposed to global economic shifts than are most countries, and its rebuilding exercise is being put to the test. ${ }^{1}$

It may be unclear exactly how design will achieve a transformation to a knowledge economy in Ireland, but it is impossible to dispute the aim. In the Irish national context, there is no way 'back', only debates about ways 'forward'. The idea of 'translation' (as opposed to 'transfer') is one widely used metaphor for making technology more personable - products, social effects, money or innovation. In the translation paradigm, technology is never studied or developed for its own sake; it is always self-consciously socially functional, bound up in a hegemony of aggressive modernisation. Bertie Ahern commented on the opening of a technology research centre at a Dublin University: 'It will enable groundbreaking research to be translated into the innovation that is needed to drive Ireland's development as a leading knowledge economy' (Bertie Ahern 2005).

Anthropology is playing an active role in this field. In interdisciplinary environments, anthropological research is famously capable of making hi-tech innovation more effective. The most widely known examples are the involvement of anthropologists in conceptualising the PC, e-mail and the Windows-style operating 
system. All the companies mentioned above employ anthropologists and ethnographers as a part of their design process. Only in one case, however, does Intel have a team of ethnographers based in Ireland in close proximity to the head office and manufacturing plant. Anthropologists are not employed in large numbers, but in small, high-impact teams; yet it is a good bet that as Ireland moves further down the road in its knowledge economy project, some anthropologists will be playing a part in this journey. It is also likely that the discipline of anthropology will increasingly experience moments of self-reflection as its members do more anthropological work within a designoriented environment (Cefkin 2009).

This is not to say that anthropology is leading the design agenda. Bannon (2000) makes the point that ethnography has raised consciousness within design of the most important issues - meaning social rather than technical issues - but has not yet had an impact on the 'subjects' of design, or on general design practice, which it ought to.

These phenomena are more than economic, but conjointly cultural. There is a bringing-toprominence of the notion of design as a selfconscious field of practice in many contexts. In a sense, design becomes viewed as a national cultural resource, ${ }^{2}$ and as 'innovation' democratised. As Attfield (1999) observes, professional design always aspires to set itself apart from the everyday world of things, and yet design pervades the everyday, and anthropology in particular should recognise this. Instances increase wherein people are not 'consumers' or 'users' of technology, but 'designers'.

\section{This issue}

Design is a tricky word. Like "technology", ... or like "Art", it sets off all sorts of alarm bells in different people.

(Batchelor 2005: 142)
This special joint issue between Anthropology in Action and the Irish Journal of Anthropology aims to stimulate the framing of those questions that anthropologists should be asking about design around technology. It does so by presenting a spectrum of papers from Ireland, ranging from studies on the everyday consumption of technological objects, to instances in which anthropologists are working on hi-tech design. At one end of the spectrum are cultural interpretations that stand back from their field, and at the other end, interpretations become more engaged, such that critique aims to both influence design and use design methods to further anthropological understandings.

As a subject for anthropology, design must necessarily be treated as a fluid field, different in every cultural circumstance and with imprecisely defined borders. Yet we have already identified it as a fit topic of study; hence what socio-cultural characteristics can we hypothesise that might typify design? If design is a group of people, then who? If it is an object, then what? If it is a set of practices, then how does it happen? Most importantly, in what ways might we expect people, things and practices to interact in ways that we could identify, with some confidence, as design?

Before we discuss these questions with regard to the papers in this volume, and then with the wider literature, let us clarify the problem better with two hypothetical examples that illustrate designed objects in relation to technology and art. We suggest that design is potentially distinguishable - 'one type of "thing" among other "things" that make up the summation of the material world' (Attfield 1999: 11) (Figure 1).

How is a car a manifestation of technology and design? Evidently, it can be either or both. We suggest that most drivers would see their car's engine as technology, while the car form and interior are more likely to be described as 'design'. One major difference is in perceptions of the object as something one can engage 


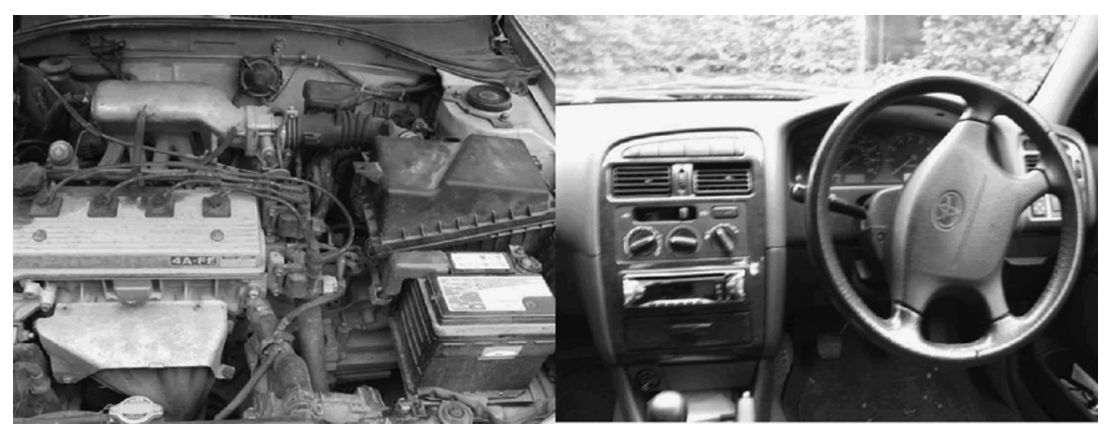

Figure 1: Design and technology. A driver may see a car engine as 'technology', while the interior and dashboard is 'design'. A mechanic conversely may talk about the engine as 'design'.

with. For most people, the engine, which is the cause of movement, does not invite meddling, but actually discourages it. It is like an impenetrable black box. Conversely, we suggest that the person who is able to dive into an engine and fiddle with the parts, such as a mechanic, is more likely to describe it as a design.

As a second example, consider clothes as art. Many artists work with textiles or with clothing forms. Susan Cross, for example, produced a piece entitled 'Gloves', which is a pair of gloves in delicate chain mail, a meditation on the expectation of softness and pliability against hard rigidity (Stoker 1993: 45). Art objects of this type would not seem out of place on a fashion catwalk; yet there is a significant, if delicate, difference between clothes as art or as design. While in an art exhibition, they evoke the possibility of being worn only as a thought experiment, on a catwalk, their wearability by the audience is a distinct possibility. They may be barely obtainable, they may look physically improbable, but nonetheless, on a catwalk, the possibility of ownership and even wearing becomes possible. 'Whereas art enchants the ordinary object and makes it special, design disenchants it,' argues Attfield (1999: 4).

The following papers all address in different ways this issue of characterising the who, what and how of design, through their treatment of technology. All are in some sense based in Ireland, either the fieldwork or the researcher. There are three kinds of papers. First, there are papers about the consumption of technological objects (Hynes, O'Brien), which produce sociological or anthropological reflections and cultural critiques. In these instances, design is simply the object of study, or rather the relations and meanings around the object provide a subject of study and critique. Second, there are anthropological studies about technological projects in workplaces (Komito; Stan and Toma). These are instances in which technology is adopted explicitly with the intention of achieving social changes. The fieldworker is working with people who explicitly have designs for change. Thus, there is a more complicated politics of design at play here, in which the perspectives of professional designers engage with the perspectives of users-as-designers. There is also a more explicit two-fold conception of design, design as material object and design as cerebral intention, a distinction we can make by talking about the 'designed object' as against the 'having of designs'. Finally, there is an article regarding the employment of anthropological methods explicitly with design in mind, and the fieldworker is conducting work within a context that 'has designs' in the longer term (Roberts and Drazin). In this instance, there is an even more complicated politics of design at play, as anthropologists themselves are drawn into the question of having designs, how the discipline of anthropology may acceptably have designs and the effort it must make in doing so to align the anthropological project with the projects of its informants. 
Hynes and O'Brien discuss two areas, each of which presents particular research issues - use of the internet and use of the mobile phone. In each case, the methodological issues of access, witnessing use and talking with people, bear testimony to the intimacy of the media. The technological object manifests itself as socially self-sufficient, both aim and means of socialisation, and researchers must proceed carefully to gain a sense of perspective. These papers fill a general gap in the literature, since studies of technology consumption in Ireland are comparatively rare.

In much of the technological design, there is a notion that the user is 'built in' to the design, such that the artefact will anticipate through the notion of 'scripts', the ways it will be employed. Hynes, by contrast, develops an understanding of the social context in Dublin homes, and argues that 'individuals design their own socio-technic relationship'. Design is instead paralleled here with appropriation and domestication, and is attuned with practices of consumption (Miller 1987, 2001). There are notions of self-improvement, keeping-up with neighbours and, beyond this, the social redemption of self and family: 'good' parents get the internet. Family members are themselves active in design through their attention to ways-of-relating. The paper dismantles the conceit that whereas professionals design, users simply consume.

$\mathrm{O}^{\prime}$ Brien is also engaged in a project of revealing how people with mobile phones have their own designs in mind. The main contribution of the paper is in stripping away the complexity of political dimensions to the mobile phone. This technological communication tool is seen as a threat to the social order in schools. Pupils have the capacity to individually engage in social connections, which create a networking-based sense of sociality conducted under-the-desk while in the public eye. Through the mobile, the intentionality of pupils is rendered significant within the politics of the school: it opens up a new possibility of seeming obedient while actually having alternative designs, and being able to act upon them. A mainstream consumer object is thus situated as subversive counter-culture.

In the second section, on technology in workplaces, Komito, and Stan and Toma throw more light on the social politics of design and technology. They are working on instances in which technological reform is being implemented. It is this 'implementation', and the fitting of technology to the workplace, that may be called design. In these cases, there are at least three principal parties involved, such that the fragmentation of perspectives around technology is very clear. The user of the object, the social scientist and the authorities pushing to implement the technology, all possess different points of view.

Stan and Toma outline the implementation of a digitalised patient records system in a Romanian hospital. While there are many dimensions to this implementation, the system functions to maximise value in the movement of information and patients through the hospital, rather than make them more efficient. On the one hand, the sense of value around medical treatment is palpable, and patients may now be offered a wider range of possibilities for how 'officially' they are treated. Thus, the system does not erode formal/informal relations within the hospital, but supports them. At the same time, there are more points for the transfer of information from one form to another, maximising possibilities for encounters and exchanges. The possibilities are multiplied for personal contacts and exchanges, and for the controversial gifts and payments that produce confidence in treatment, support adequate staff incomes and are blamed for clogging up the system.

Komito presents a closely argued comparable piece, investigating the development of a paperless system in a section of the Irish civil service. By contrast with Stan and Toma, a lot of attention is given in the Irish civil service to the specific work areas and functions that 
a new paperless technology is supposed to address, rather than seeing as self-evident the need for an unspecified transformation of social relations by technology. Resistance to the scheme and persistence of paper may not be of great surprise, as moves to paperlessness flounder in many types of workplaces. More interesting is the rooted culture of face-to-face contact and speech. An average of 2.5 e-mails per worker per week indicates extreme resistance to writing, even in an informal mode, when personal contact or telephoning is possible. Komito also suggests an actual aversion to digitalising information, the control of which is too precious to relinquish.

These two studies of workplaces, like the preceding articles on consumption, demonstrate the appropriation of technology. People form their own relationships, identities and designs around technology. In addition, however, both Komito, and Stan and Toma question simplistic assumptions about sociality. The types of relationships and meanings constructed are not necessarily altruistic nor even beneficial, in contrast to the presumptions about sociality that are sometimes made in professional circles outside anthropology. Here, partial access and control of information and resources appear to be the rule, not the exception.

Drazin and Roberts present an example of anthropological work conducted on material culture, to inform product design. Importantly, such work aims first to gain understandings of socio-cultural relationships, and second to develop this for a design audience. At the heart of the work is the suggestion that any such project should be realised as a potentially critical exercise, rather than as an exercise in discovering the 'unmet needs' of informants. In order to achieve this dialogue, a two-stage research method is used. A more open-ended fieldwork approach is succeeded later by discussion of the design notions involved, intending to enable critique within the contexts of informants' own physical and cultural worlds.
Working within the design-oriented environment of a commercial company, this last paper is much more explicit about the notion of design and where anthropology stands in relation to it. Informant, professional designer and anthropologist are here all situated within the project of design. There is in this instance no 'designed' object in current existence - the designed thing or service is a future possibility. Thus, design appears as a set of practices, which includes, at a certain stage, anthropological practices.

Taken together, these papers demonstrate the enormous imperative drive towards design, and how it is socially distributed. In Ireland and elsewhere, people in homes, workplaces and within anthropology are all harnessed into the journey of design. At the same time, all of the papers reveal design as a highly contested field, and take critical stances to the subject. If there is an imperative for anthropology, it is not doing design, but determining in what ways design and the designed object may be fit and distinct subjects for study. We can begin this process by examining approaches to technology and to agency.

\section{The anthropology of technology}

The list of authors who have written about the anthropology of technology is long, impressive, eminent and impossible to adequately reproduce in a short introduction such as this. The study of technology calls for both an appreciation of the consumption and use of the technological object (Silverstone and Hirsch 1992; Garsten and Wulff 2002), and of perceptions of social modernity and progress around objects. The unqualified assertion that 'technology $=$ social progress' (implied by some Irish politicians) is long past its sell-by date in anthropology. Eglas calls this the 'impact' (2007: 330) school of studying technology, and it has long been superseded by approaches influenced by social constructivist thinking, 
which look at meanings, relationships and knowledge (e.g., Bijker et al. 1987; Lemonnier 2002). A parallel set of approaches draws its roots from early anthropology (Mauss 1990, Malinowski 1978) to deconstruct personobject dualities, such that persons are seen, in some sense, as technological (e.g., Haraway 1991).

The most prominent arguments to address the links between agency and technology have been around an actor-network theory (ANT; Latour 1987, among others). The personalisation of the technological object is central to these debates. Grint and Woolgar (1997) draw on the metaphor of the deus ex machina to reflect on the cultural conceptions of what an 'idealised' machine is. ${ }^{3}$ The deus ex machina is a theatrical device, both plot device and physical machine: 'an unexpected saviour, or ... an improbable event that brings order out of chaos' (1997: 3). At the key climactic moment, when the characters are bound up in apparently unresolvable complications, the machina may appear on stage. The machine generally lowers a deity or spirit from above, perhaps wreathed in clouds of smoke or dazzling light effects, who then neatly resolves all the difficulties. The machine and the spirit are one, intensely moralised, embodying either the Divine or the Satanic.

What the idealised machine enables us to conceive is the appearance of unity in technology, of the technical as knowledge (techne - know-how or a rational process) and as object (Crabtree 2003; Button 1993). In dwelling on the 'unexpectedness' of the machine, Grint and Woolgar are drawing attention to the way in which technology is itself seen as causal, the originator of effects, and while it is perhaps like a person, it is not one. The quality of efficacy, generally linked with agency, is strongly objectified. Consequently, the maker or inventor of a piece of technology is, with some notable exceptions, forgotten or 'left behind' when the machine is working, and the object itself takes credit for effects. In this vein, Strathern (1992: xiii) describes the type of agency that accrues to the consumer of technology as 'processor', an agent only in as much as they are 'author of how things will be consumed' (ibid.). While people may channel the effects of technology, technology itself will appear as the source of change. Latour (2000: 113) reminds us how technology actually structures social organisation, and does not merely reflect it. Miller (2002: 7) meanwhile suggests that this objectification is itself commonly problematic, because the object that resists appropriation attempts to impose new, unrealistic practices of use: 'the problematic reification of ideals of new technology separated out from its practice'.

\section{Design as culture: designed objects and the having of designs}

The anthropology of design remains less defined than the anthropology of technology or art, although work has begun to snowball in recent years. Since the 1980s, there has been a move to 'acculturise' design: authors began looking at relationships between design and culture (e.g., Sparke 1986; Pye 1982), and have come to discuss design as an element of culture (e.g., Attfield 1999; Shove et al. 2007; Julier 2007). The study of design has been a part of the redirection of attention towards popular culture, the everyday and commercial culture. By contrast, both technology and art have inspired relatively clear theories of the manifestation of subject-object relations and meanings (specifically Gell (1998) on art and agency, Latour (1987) on technology).

The example of Ireland moving 'into design' demonstrates the expectation that the field of design effects certain kinds of social or cultural work that cannot be carried out by artistic or technological fields. To explore this, let us return to the theme of the idealised designed object. Consider the sense of talking about 'a design'. In popular discourse, the subject of a design is not as reified as technology or art; 
instead, 'a design' implies explicitly and consciously a compound of a thought and a thing together. In talking about 'design', people are able to talk, not about material things per se, but about the relation between thing and thought. In effect, design is one way in which people can consider subject-object relations at an everyday level.

Representations of design in the public domain in Ireland make a number of distinctions. First, there is a relationship being expressed to time and causality. Like technology, design is seen as progressive and directly involved with social change. However, the ideal technology (Grint and Woolgar 1997) causes change itself. It is without social precedent, and is an origin of change. Design discourses meanwhile are more about engagement, how we can engage with, and in, processes of change.

Convergent with this conception of design is the way that the designed object is often more personalised, a manifestation of the thoughts of the designer. Technologies have inventors, but live their own lives. Often there is popular ignorance regarding who invented a technology; and if people know, there is still no need or social pressure to know. In this sense, meaning the way in which it is reified, design is more like art than technology. The agency manifested in the designed object is indisputably pre-figured by persons.

Representations of design also illustrate particular conceptions of the efficacy of objects. Both an innovative painting and a new form of mobile phone have social effects, but of different kinds, and the differences lie not only in the attribution of causality but in the type of effect. Attfield (1999: 12) lists examples of what design exercises or objects can be intended to do 'fulfil a particular task, to make a statement, to objectify moral values, or to express individual or group identity, to denote status or demonstrate technological prowess, to exercise social control or flaunt political power'. This list seems general, but is interesting in that it places first the kinds of effects that are generally secondary for art or technology. Art's effects are generally considered to concern cognition and ways of knowing, of an almost magical kind (Gell 1998), while technology mostly shapes practice and knowing 'how', with particular emphasis on production. Attfield's list is primarily about effecting change in the sociocultural field directly, not secondarily. Design is socialising, and is seen as good in the same way that society is generally a good thing. It has a redeeming function, by which people are taken account of and the material world is rendered 'appropriate'. Negative effects of an object are more likely to be ascribed to its 'technological' than 'designed' qualities.

The argument, then, is broadly that design merits anthropological study in its own terms. The point of comparing design with technology and art is not to define design in some concrete manner - the terms of comparison are arbitrary - it is merely to illustrate that design is not merely a space in which art and technology overlap, but a cultural field with distinctive characteristics.

- The idealised technological object or machine is seen as a source and originator of change, pre-existent to social effects, and strongly reified. The effects of technology are seen as 'real', existing first in the world of praxis and materials.

- The art object manifests human agency, its causality attributed to the artist and their prior thinking. The effects achieved are also generally cognitive first.

- The idealised designed object exists as a compound of creator and object, like art. It is bound up within processes of change, seen as progressive, like technology, but not as a fount of change. Its efficacy can be about praxis and cognition, but is primarily social.

In negotiating the balance between intentionality and efficacy, design is one way in which the qualities of agency in objects are 
negotiated. Ahern (2003: 109) defines agency as 'the socio-culturally mediated capacity to act', while other approaches place emphasis on the materialisation of the mind (e.g., Gell 1998), and on the presence of persons. The exact way in which agency is compounded varies: Strathern (1999: 17) points out how in Euro-American societies, intentionality and will are often elided. Intending or planning to do something does not necessarily imply that one wants or wills it, but they can be culturally seen to be coincident.

The culture of design thus places emphasis on the negotiation between the design (the object or manifestation) and the having of designs (the thinking), and this is reflected in different ways in the articles in this issue. For Komito, 'design' is about the appropriateness or fitness of technology for particular civil service tasks, and references to design coincide with mentions of management approaches to the organisation. In the event of implementing a paperless technology, a parallel set of concerns emerge, which find their focus in the paper files. The staff are interested in ways of denoting responsibility, and in reading 'behind' a set of information for the personal intentions of colleagues. The cases they work with have personal biographies, they are not only caches of information, and paper artefacts suit these purposes better than do digital screens. While in an official sense, it is only questions of appropriateness around the 'technological' object that are sanctioned as 'design', Komito is concerned with expanding these questions to wider networks of personalisation and intention around paper.

For Stan and Toma, the implementation of an IT system is at one level much more like the Deus Ex Machina. It is purportedly about effecting a purifying 'messianic vision' of change in Romanian hospitals, their practices, their relationships and their institutional culture. Hospital staff regard the system a bit differently, as a manifestation of personal relationships in various ways: for example, between the Ministry of Health and American software companies. From neither perspective does the question arise of appropriateness for hospital staff and tasks, but staff and patients are nonetheless concerned with the social effects of the system, such as its capacity to negotiate being treated 'officially' or 'legitimately'.

The internet-linked computers that Hynes discusses fall most clearly in the category of design, because of the way in which they are used to achieve social functionality. The internet becomes an explicit manifestation of the good intentions of parents to fulfil responsibilities for their families. Likewise, O'Brien is interested not in the technical capacities of mobile 'phones (to call or text from anywhere), but in the implementation and the intention to use them. Even if unused, mobiles capacitate a sense of social commonality. In conclusion, O'Brien notes that even without 'conscious designs' at an individual level, pupils come to share a common set of 'dispositions'. There are thus subtle distinctions being made about the origination of socially mediated intentionality around technology and of that in the mind.

For Drazin and Roberts, design is a contested and conflictual field, in which the way forward comprises in trying to reconcile the designs different actors have. In addition to the involvement of professional designers, some informants have explicitly 'designed' their lives, while for others it is a day-to-day process. The technology here is hypothetical, a future possibility, and the entry point into the designs people have is instead artistic. This changes the scope of the research somewhat. The artistic collages are specific and point-like in their social and methodological remit, covering the designs of an individual or family at a moment in time; it is through their translation into technological design that they may have wider impact.

As we discussed at the outset, design is not a universally distinct field or thing, but nonetheless it is recognisable in situ. We recognise design in the interior of a car (Brenna et al. 1998), 
in its surfaces (Ingold 2000), inviting touch in ways which the engine does not. There is an act of 'reaching out' by the clothes on a catwalk or shop window, which is not present in the clothes in a glass case in a museum or gallery. Fashion offers the possibility of engagement and actually being physically worn, and in this way aspires to having popular social effects.

There are thus recognisable and recurring themes in these articles, and to discuss them, the most apt term we can use is 'design', with a consciousness of its plurality of referents. Design exists in the space between the designer and the user, mutually bound together. While the creation of art or invention of technology can potentially be a wholly self-absorbed activity, in design, the pressure is always on transcending this problematic state of individualised self-ness. Design moves to achieve compounded agent-like unities that are much larger than the individual person, and which negotiate the boundaries of inclusivity and exclusivity in a fluid sense. Many designed objects appear as exclusive, this is undeniable, but in that exclusivity is also contained an invitation to belong. Some designs are populist, and more overtly democratic in their inclusivity. There is an attention to surfaces and form in design, and a consequent tension between the inconsequentiality of thought and the substantiality of effect. An encounter with a designed object is not necessarily problematic in the confrontational, out-of-control colliding sense of technology or art - for which Gell (1998: 20-21) famously used the metaphor of the landmine, reminiscent of debates over the agency of a soldier and/or gun (Latour 1996; Lemmonnier 1996). Designs are not quite 'without precedent' like technology. Aiming at being un-magical, graspable, comprehensible, admired without being mysterious and engaging without being enchanting (Attfield 1999), the designed object is one that can stand beside you rather than before you. In a sense, an elision of will and intention is attempted in the agency of design.
Design is strongly concerned therefore with issues of social legitimacy: how what is done socially may be intended, and how what is intended may be wanted.

\section{The encounter with design and directions for research}

The articles in this journal illustrate the ubiquity of anthropological encounters with design issues in their workplaces and field sites. At the extreme, every time you open a web page you engage with design. What does this spiralling encounter with design mean for anthropology as a discipline? The most intense engagement is in professional design projects, by anthropologists working with the discipline of design alongside design professionals. Blomberg (2009) observes that anthropologists in corporations tend to write more self-reflective material than those in university settings, proportionately speaking. Engagement with design seems to be provoking anthropologists to think in new ways about what anthropology constitutes. These debates are being conducted in the literature (Frascara 2002; Cefkin 2009), at conferences such as EPIC (Ethnographic Praxis in Industry), in many blogs and in journals such as Pervasive Computing, CSCW (Computer-Supported Cooperative Work) and Anthropology in Action among others.

Bringing a design project forward frequently necessitates a multi-disciplinary team that draws on different skills, either according to a plan or pragmatically (Suchman et al. 1993). This means that at times the team is doing anthropological work (e.g., ethnography), including non-anthropologists such as engineers, photographers or psychologists. At other times, anthropologists are doing work such as lab-testing of prototypes or creating storyboards. At times, consultancy is required, a commentary from an anthropological perspective, rather than fieldwork. This experience, project by project and year after year, 
scrutinises anthropology, clarifying when anthropology is praxis, when it is epistemology and when it is expertise.

Through experience, the anthropologist in design may realise that this situation is not necessarily a problem. You can be an anthropologist without, right now, doing anthropology. The value of well-practised, well-promulgated anthropology in the hi-tech field is relatively established (though levels of ignorance about what anthropology is, remain astounding), and it becomes clear during an early career what an anthropologist can and cannot do well: we are trained in cultural commentary, not in actually designing. Core anthropological competencies thus emerge, perhaps after a steep learning curve. Much of the work emerging from this field is not afraid to be working on the borders and in grey areas (Drazin and Roberts, this issue), negotiating how the specific things being done are anthropological, and how they are not. The result is sometimes a surprisingly purist attitude to what anthropology is. The experience of working 'on the borders' results in a sense of control, which few postgraduates gain during training. Rather than answering other disciplines' questions, design anthropologists often begin to pose anthropological questions for designers and engineers to answer.

There are valuable opportunities for intradisciplinary critique in this situation, especially with regard to praxis. It can be difficult for academics to gain a perspective on their own work, when the definition of work conducted in an anthropology department verges on the tautologous. An anthropologist in a company, fighting their corner daily with many people who do not (yet) know nor appreciate what anthropology is, may feel a degree of concern to get the details correct. It is not a problem, we suggest, if an anthropologist uses methods devised for historical, psychological or sociological research purposes. However, to be unaware of it, is unforgivable. An example might be discussion groups, a worthwhile method for many purposes, conceived by psychologists (Imms 1999) to exclude all the data on everyday life that anthropology normally thrives on.

There are also opportunities in corporate design anthropology for the contestation of specific ideas and arguments. Recent critical work on context (Dilley 1999), for example, is scrutinized in terms of its communication in spheres such as 'context-aware computing' (Dourish 2004; Räsänen and Nyce 2006), in which the notion of context has consciously pragmatic and embodied resonances. Design offers tools for cultural critique, possessing a critical tradition that has grown in recent years (Dunne 2008; Dunne and Raby 2001; McDonough and Braungart 2008). We may find valuable tools in design for anthropological purposes.

There are a range of areas therefore where design anthropology is offering significant contributions to the discipline, beyond simply being 'an application' of anthropology and a subject of significant ethnographic work (e.g., Garsten 1994). It is probably in the field of anthropology-as-praxis that there is most scope for producing major self-critiques.

There are significant debates on ethics and politics that can arise from working in this area. In one way, the issue is who we work for, but it is not the only one: anthropologists are working on design in the public sector, private sector, charities, hospitals, academia and elsewhere. Making employment possibilities explicit is here an essential first step to making ethical debates more explicit. Many anthropologists training in development are probably unaware that some of them will be furthering their humanitarian aspirations in private profit-making companies or, for example, in the military. These are valid careers, but not ones to sleepwalk into. The lively design anthropology forum on the web is one of the places where such possibilities are seriously debated. This is how anthropologists can become equipped to make career decisions, and to say 'no' or 'yes'. 
More fundamentally, design itself has resonances for political philosophy. While design shares with policy and development fields a humanitarian project of personal and social amelioration, it goes about its work in particular ways. Taking design seriously implies a materialist conception of the world. By this, we mean it is about restoring the balance identified by Christina Toren when commenting that 'The ideal and the material are mutually specifying' (Toren 2006: 207). The anthropological product has tended to lie more on the 'ideal' side of this equation - an idea, critique, interpretation or way of thinking. Design anthropology by contrast aims to gain its leverage through material change (albeit usually after many years of ideas, critiques and conceptualisations). As Cross (2006: 1) put it, 'the central concern of design is "the conception and realisation of new things". This materialist trajectory is probably what best distinguishes design anthropology, rather than where it is practised or with what aim. Frequently, the design exercise is problematic and even damaging: Miller (1984) has given a damning critique of elitism around modernist architectural design from the simple observation that those doing the designing did not physically live in their own designs. An engaged anthropology has a role in attempting to improve this kind of exercise.

The political implications of this materialist orientation demand debate and evaluation, which will only happen in the long term. First, a specific and fine-grained focus can be more useful for design than a broad investigation of culture or society. Traditionally, policyoriented anthropology draws on research into the specific, but finds it useful to draw out from individual instances to broad categories of class and social structure. Many designoriented approaches by contrast find inspiration in the particularities of a situation, but find no material inspiration in the social structure. In effect, any product or service produced is itself the demonstration of social understanding.

The materialist reasoning also means that design anthropology may be particularly suitable for working with certain informants: specifically, those who mistrust the idea of being the subject of policy-based approaches. This is a complicated issue, one which also needs much deeper specification and debate in the discipline. The anthropologist's commitment, often a 'lifetime commitment' (Bernard 1995: 164), is primarily to informants. The problem is that many of those whose lives might be best ameliorated by changes stimulated by either policy or design are exactly those who may shun involvement with policy bodies. Anthropology has debated this issue at length and with pragmatism in development circles: it is a truism that those most at risk of state persecution can be most dependent on the state. It is likewise a truism that those at most risk of being profited from through commodities can seem most dependent on them, but until relatively recently anthropological attention to the corporate point of view (often critical) was divorced from understanding the perspectives of the people who purchase and use goods. Many progressive approaches have in this area unfortunately forgotten the mutuality between material and ideal, which Toren reminds us of, and even some traditions with materialistic roots would now see analysis of abstracted social structure as their only engaged anthropological contribution. An over-specification of social structure and class can seem problematic to some informants, particularly if not accompanied by material and praxis referents. In short, in some instances, a materialist-oriented design anthropology is the most apt approach, but we need to better discriminate when.

\section{Conclusion: making design manifest}

The exercise of this introduction has been speculative. We have scratched the surface 
of the literature, moving from the socio-cultural background of Ireland to indicating the broader implications of an anthropological engagement with design and technology. We hope we have provoked readers into an admission that a lot of work remains to be done in terms of these subjects. In particular, we hope we have shown that the 'designed object' is a particularly interesting and distinctive thing for anthropology to investigate.

Design often concerns different ways of culturally negotiating explicit dichotomies of form and intention, of movement between what is done and what is intended. The distinction between design as object and the having of designs needs further elaboration, exploration and critique.

There are reasons for distinguishing design from technology and art, although they frequently coincide. Design displays a primary concern with effects in the social or cultural field: such as making or breaking relationships, including or excluding people, legitimising, or redeeming in a social sense, concerns that are, for technology, secondary to shaping practice, and for art, secondary to shaping cognition. An encounter with a designed object is like an invitation for inclusion. While Gell (1996) compares art to traps, intriguing and cognitively 'sticky', yet potentially overwhelming of its audience, design is not unconquerable in the same way. It excludes while inviting membership; it offers the potential for possession while, in many cases, being hard to obtain. Design negotiates this interface of exclusivity and inclusivity, and offers the capacity to act upon it.

The articles in this journal all focus on technological design, but in a particular manner. They all describe movements to develop wider senses of participation, and conscious attempts to create forms of social agency that are both augmented and distributed. Every paper makes manifest and explicit certain problems and sites of contestation, which invite the engagement and application of anthropology.
Adam Drazin is an anthropologist who lectures in the Department of Sociology, Trinity College, Dublin. He also conducts a course on anthropology and design, jointly between the National College of Art and Design and the Department of Anthropology at Maynooth. His prime interest is in material culture and social uncertainty, with a dual focus on applied design, and on Romanian domestic material culture in different countries. He has worked as a design anthropologist for Hewlett-Packard Labs, for Intel and for the University of Eindhoven, and has his own consultancy business. He has published in journals including Ethnos and Home Cultures, and is working on a book on Irish-Romanian Homes and cultures of openness.

Pauline Garvey completed a PhD in Anthropology from University College London in 2002. Since then she has published several works on consumption and domesticity in Norway. She is a lecturer in anthropology at the National University of Ireland, Maynooth. She is currently conducting research on Swedish design, social democracy and IKEA consumption in Stockholm and Dublin.

\section{Notes}

1. Ireland's stated aims have only gradually been matched by government funding. Only in 2007 did spending on R\&D reach OECD average levels, and the 2006 Strategy for Scientific Technology and Innovation stated an aim of increasing funding from $1.6 \%$ of GDP to $2.5 \%$ by 2010 (Sources: Forfas 2008; SSTI 2006).

2. As, for example, in some Scandinavian countries, known internationally for 'design' first, and second for 'technology' or 'art'. directly links Scandinavian Design traditions to local forms of industrial relations and democracy.

3. What makes an object 'technology' clearly varies - ipods, leggings, telephones, gas lights, windows, stone axes, all of these have at some time been typical technological objects. So we can think about this through 'idealized conceptions of the nature of technology' (Grint and Woolgar 1997: 3). 


\section{References}

Ahern, B. (2003), 'Statement by the Taoiseach, Mr. Bertie Ahern T.D., Prime Minister of Ireland at the Plenary Session, United Nations World Summit on the Information Society, Geneva, Thursday, 11 December 2003', <http:/ /www. itu.int/wsis/geneva/coverage/statements/ ireland/ie.pdf> (accessed 12 January 2009).

- (2005), 'Speech by an Taoiseach, Mr Bertie Ahern T.D., at the formal launch of InVent as DCU's "Commercialisation Gateway" and the opening of the Biotechnology Labs in DCU, 8 July 2005', < http:/ / www.ndp.ie/view doc.asp? DocID $=56>$ (accessed 9 January 2009).

Ahern, L. (2001), 'Language and Agency', Annual Review of Anthropology 30: 109-137.

Attfield, J. (1999), Wild Things (Oxford: Berg).

Bannon, L. (2000), 'Situating workplace studies within the human-computer interaction field', in Workplace Studies: Recovering Work Practice and Informing System Design, (ed.) P. Luff, J. Hindmarsh and C. Heath (Cambridge: Cambridge University Press), 230-242.

Batchelor, R. (2005 [1984]), 'Not Looking at Kettles', in Interpreting Objects and Collections, (ed.) S. Pearce (London: Routledge), 139-143.

Bernard, H. (1995), Research Methods in Anthropology: Qualitative and Quantitative Approaches, 2nd edn. (Lanham, MD: AltaMira Press).

Bijker, W., Hughes, T. and Pinch, T. (eds.) (1987), The Social Construction of Technological Systems (Cambridge: MIT Press).

Blomberg, J. (forthcoming 2009), 'Insider Trading: Engaging and Valuing Corporate Ethnography', in Ethnography and the Corporate Encounter, (ed.) M. Cefkin.

Brenna, B., Law, J. and Moser, I. (eds.) (1998), Machines, Agency and Desire (Oslo: TMV Skriftserie).

Button, G. (ed.) (1993), Technology in Working Order: Studies of Work, Interaction and Technology (London: Routledge).

Cefkin, M. (ed.) (forthcoming 2009), Ethnography and the Corporate Encounter: Reflections on Research in and of Corporations (Oxford: Berghahn).

Crabtree, A. (2003), Designing Collaborative Systems: A Practical Guide to Ethnography (London: Springer-Verlag).
Cross, N. (2006), Designerly Ways of Knowing. (Key paper first published in 1982) (London: Springer-Verlag).

Dilley, R. (ed.) (1999), The Problem of Context (Oxford: Berghahn).

Dourish, P. (2004), 'What we talk about when we talk about context', Personal and Ubiquitous Computing 8, no. 1: 19-30.

Dunne, A. and Raby, F. (2001), Design Noir (London: August/Birkhäuser).

Dunne, A. (2008), Hertzian Tales: Electronic Products, Aesthetic Experience and Critical Design (Cambridge, MA: MIT Press).

Eglas, R. (2007), 'Technology as Material Culture', in The Handbook of Material Culture, (ed.) C. Tilley, W. Keane, S. Küchler, M. Rowlands and P. Spyer (London: Sage), 329-340.

Ehn, P. 'Scandinavian Design: On Participation and Skill', in Participatory Design: Principles and Practices, (ed.) D. Schuler and A. Namioka (Hillsdale: Lawrence Erlbaum Associates), 41-78.

Forfas. (2008), The Science Budget 2007/2008 (Dublin: The National Advisory Board for Enterprise, Trade, Science, Technology and Innovation).

Frascara, J. (ed.) (2002), Design and the Social Sciences: Making Connections (London: Taylor \& Francis).

Garsten, C. (1994), Apple World: Core and Periphery in a Transnational Organizational Culture (Stockholm: University of Stockholm).

Garsten, C. and Wulff, H. (eds.) (2002), Technologies at Work (Oxford: Berg).

Gell, A. (1996), 'Vogel's Net', Journal of Material Culture 1, no. 1: 15-38.

- (1998), Art and Agency (Oxford: Phaidon).

Grint, K. and Woolgar, S. (1997), The Machine at Work: Technology, Work and Organisation (Oxford: Polity Press).

Haraway, D. (1991), Simians, Cyborgs and Women: The Reinvention of Nature (London: Free Association Press).

Imms, M. (1999), A Re-Assessment of the Roots and Theoretical Basis of Qualitative Market Research Conference Papers of the MRS Conference (London: The Market Research Society).

Ingold, T. (2000), The Perception of the Environment: Essays in Livelihood, Dwelling and Skill (London: Routledge).

Julier, G. (2007), The Culture of Design (London: Sage). 
Latour, B. (1987), Science in Action: How to Follow Scientists and Engineers Through Society (Cambridge, MA: Harvard University Press). - (1996), 'Lettre à mon ami Pierre sur l'anthropologie symétrique Culture materielle et modernité', Ethnologie Française 26, no. 1: 32-37.

- (2000), 'When Things Strike Back: A Possible Contribution of "Science Studies" to the Social Scientists', British Journal of Sociology 51, no. 1: 107-123.

Lemmonnier, P. (1996), 'Et pourtant ça vole! L'ethnologie des techniques et les objets industriels Culture materielle et modernité', Ethnologie Française 26, no. 1: 17-31.

- (ed.) (2002), Technological Choices: Transformation in Material Cultures Since the Neolithic (London: Routledge).

Malinowski, B. (1978), Argonauts of the Western Pacific (London: Routledge).

Mauss, M. (1990), The Gift (London: Routledge). McDonough, W. and Braungart, M. (2008), Cradle to Cradle: Remaking the Way We Make Things (London: Jonathan Cape).

Miller, D. (1984), 'Modernism and suburbia as material ideology', in Ideology, Power and Prehistory, (ed.) C. Tilley and D. Miller (Cambridge: Cambridge University Press). - (1987), Material Culture and Mass Consumption (London: Routledge). - (ed.) (2001), Home Possessions: Material Culture Behind Closed Doors (Oxford: Berg).

. (2002), 'Introduction: from people of the book to people of the screen', in New Technologies at Work: People, Screens and Social Virtuality, (ed.) C. Garsten and H. Wulff (Oxford: Berg), 7-24.

Pye, D. (1982), 'Six Requirements for Design', in Material Culture Studies in America, (ed.) T. Schlereth (Nashville: American Association for State and Local History), 153-161.

Räsänen, M. and Nyce, J. (2006), 'A New Role for Anthropology?: Rewriting "Context" and "Analysis" in HCI Research', NordCHI 2006: 175-184.

Shove, E., Wilson, M., Hand, M. and Ingram, J. (2007), The Design of Everyday Life (Oxford: Berg).

Silverstone, D. and Hirsch, E. (eds.) (1992), Consuming Technologies (London: Routledge).

Sparke, P. (1986), An Introduction to Design and Culture in the Twentieth Century (London: Routledge).

Stoker, R. (1993), 'Designer Makers UK', in Curators and Collections, (ed.) N. Wegner and S. Batiste (London: Cv Publications), 44-47.

SSTI. (2006), Strategy for Science, Technology and Innovation 2006-2013 (Ireland: Government of Ireland).

Strathern, M. (1992), Reproducing the Future: Essays on Anthropology, Kinship, and the New Reproductive Technologies (London: Routledge).

- (1999), Property, Substance and Effect: Anthropological Essays on Persons and Things (London: Athlone).

Suchman, L., Schuler, D. and Namioka, A. (1993), Participatory Design: Principles and Practices (Philadelphia: Lawrence Erlbaum Associates).

Toren, C. (2006), 'Introduction to Mind, Materiality and History', in Anthropology in Theory: Issues in Epistemology, (ed.) H. Moore and T. Sanders (Oxford: Blackwell), 204-219. 